\title{
Hans Kuhn
}





\section{Hans Kuhn}

\section{Kleine Schriften}

Aufsätze und Rezensionen aus den Gebieten der germanischen und nordischen Sprach-, Literatur- und Kulturgeschichte

Dritter Band

Namenforschung

Sonstiges

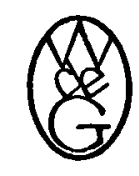

Walter de Gruyter · Berlin · New York

1972 
Kleinere Schriften zar Literatur- und Geistesgeschichte

Herausgegeben von

Dietrich Hofmann

in Zusammenarbeit mit

Wolfgang Lange und Klaus von See

()

ISBN 311004109

Library of Congress Catalog Card Number 71-431553

Copyright 1972 by Walter de Gruyter \& Co., vormals G. J. Göschen'sche VerlagshandlungJ. Guttentag, Verlagabuchhandlung - Georg Reimer - Karl J. Trübner - Veit \& Comp. Printed in Germany - Alle Rechte des Nachdrucks, der photomechanischen Wiedergabe, der Herstellung von Photokopien, auch auszugrweise, vorbehalten. Satz nnd Druck: H. Heenemann KG, Berlin 